\title{
The effects of Pilates and yoga participant's on engagement in functional movement and individual health level
}

\author{
Eun Ju Lim', Jeong Eon Park,* \\ ${ }^{1}$ Korea Pilates Federation, Seoul, Korea \\ ${ }^{2}$ Department of Early Childhood Education, Pukyong National University, Busan, Korea
}

This study was conducted to investigate the effect of Pilates and yoga participating in their functional movement and individual health level. Ninety volunteers were randomly divided into three groups and evenly recruited female and male participants in each group through a reliable organization. Their age group was between the 30 s and 40s. They were informed the research process and assigned to the consent form. Pilates group $(n=30)$, yoga group $(n=30)$, and control group $(n=30)$ were assigned to fulfill short form of Rand 36-item health survey (SF-36) survey form based on self-administration method and were scored functional movement screen (FMS) test before the intervention. Pilates and yoga group were carried out certain exercise program 1-hr duration 3 times per week for 8 weeks. And control group did not perform any exercise during experimental period. After completion of the 8-week Pi- lates and yoga program, they recorded SF-36 and were scored FMS score for posttest in same way. When we compared the differences between pre- and posttreatment scores, we found that there was statistically significant difference among three groups on FMS ( $F$ $[2,89]=15.56, P<0.001)$ and there was significant change in favor of $\mathrm{Pi}-$ lates group groups $(F[2,89]=52.36, P<0.001)$ on SF-36. To conclude, $\mathrm{Pi}$ lates group was more effective for improving functional movement and individual health level to assess quality of life than yoga group and control group.

Keywords: Pilates, Yoga, Functional movement screen, Individual health level

\section{INTRODUCTION}

The World Health Organization defines health as "a complete state of physical, mental and social well-being and not merely the absence of disease or infirmity" (World Health Organization, 2006). As such, health-related quality of life includes physical, psychological, social and economic aspects along with absence of disease. In modern times, mental stress, chronic pain, and physical limitations are having a negative impact on health-related quality of life (Klerman, 1981). One proven means to improve health is an exercise which has the demonstrated ability to improve both physical and psychological quality of life (Küçük and Livanelioglu, 2015).

Recent research continues to support the assertion that exercise is an important foundation for good health and quality of life.
Duggal et al. (2018) reported that people who consistently engage in exercise over their entire life tend to live longer with improved health. While numerous options are available for exercise, individual limitations need to be considered to ensure ability, safety, and suitability for long-term adherence.

As forms of exercise, Pilates and yoga each have been demonstrated to have direct benefits on both physical and mental health through improvement of posture, flexibility, muscle tone, cardiovascular function, weight management, and stress reduction. In elderly women, Pilates was shown to improve functional autonomy, static balance and quality of life (Siqueira Rodrigues et al., 2010). Pilates was also shown to improve dynamic balance, flexibility and strength in a study of people 65 years and older (Irez et al., 2011). Pilates and yoga also have demonstrated benefits for mental health, resulting in changes in participants' exercise beliefs
${ }^{\star}$ Corresponding author: Jeong Eon Park (iD https://orcid.org/0000-0002-3392-2197 Department of Early Childhood Education, Pukyong National University,

45 Yongso-ro, Nam-gu, Busan 48547, Korea

E-mail: teeny2357@gmail.com

Received: May 31, 2019 / Accepted: June 20, 2019
This is an Open Access article distributed under the terms of the Creative Commons Attribution Non-Commercial License (http://creativecommons.org/licenses/by-nc/4.0/) which permits unrestricted non-commercial use, distribution, and reproduction in any medium, provided the original work is properly cited. 
as well as physical and psychosocial parameters (Küçük and Livanelioglu, 2015).

Ideally, exercise should be practiced so that both physical and mental health benefits and are achieved and are balanced. One element of physical wellness is ease in doing motions of daily of life like sitting, standing, and lifting. These activities have the potential to cause injury but the risk of injury can be decreased through doing Pilates or yoga, as these exercises promote an expanded range of motion, balanced muscle development, and improved balance with functional movements. In regards to mental health, Pilates and yoga have been shown to promote mental clarity, focus on positive thoughts, reduced stress, and coping ability (Adams, 2018; Mental healthy, 2019).

Recent studies have shown that quality of life can be enhanced through the use of Pilates or yoga (KauricKlein, 2019; Rahimimoghadam et al., 2019; Vancini et al., 2017). However, there is not much research comparing the effectiveness of Pilates and yoga. This study set out to determine if engagement in and sustaining a Pilates or yoga exercise program results in improvements in functional movement and/or perceived quality of life among adults in their 30s and 40s. The findings could be of potential utility to health care professionals and counselors providing advice to patients to assist in overcoming their functional movement limitations. Additionally, these findings could assist in the formation of public policies focused on promoting physical and mental health. It could serve as a cost-effective way to promote overall health amongst the general public and thus reduce medi-

Table 1. General features of the study subjects

\begin{tabular}{lccc}
\hline Variable & Control group & Yoga group & Pilates group \\
\hline Age (yr) & & & \\
$30 s$ & $22(73)$ & $21(70)$ & $13(43)$ \\
$40 s$ & $8(27)$ & $9(30)$ & $17(57)$ \\
Gender & & & \\
Male & $15(50)$ & $15(50)$ & $15(50)$ \\
Female & $15(50)$ & $15(50)$ & $15(50)$ \\
Exercise & & & \\
Yes & $6(20)$ & $0(0)$ & $7(8)$ \\
No & $24(80)$ & $30(100)$ & $83(92)$ \\
Regular exercise & & & \\
Yes & $1(3.3)$ & $0(0)$ & $2(1.8)$ \\
No & $29(96.7)$ & $30(100)$ & $88(79.2)$ \\
Exercise method & & & $6(6.7)$ \\
Yes & $5(16.7)$ & $0(0)$ & $84(93.3)$ \\
No & $25(83.3)$ & $30(100)$ & \\
\hline
\end{tabular}

Values are presented as number (\%). cal expenses.

\section{MATERIALS AND METHODS}

\section{Participants}

The participants in the present study were 90 adults from South Korea. Participants were selected from Yoga Community and Korea Pilates Federation, two reliable organizations from which instructors were recruited who assisted in identifying participants. All participants were taking their first Pilates or yoga class or did not have experience with Pilates or yoga for the control group. The participants were of ages between the 30s and 40s and were evenly divided males and females. To identify their exercise status, three questions were asked in this study. First, 'I do exercise for health.' Second, 'I do regular exercise.' And third was 'I follow an exercise program.' Including exercise status, the general features of the study subjects are shown in Table 1.

\section{Experimental design}

The experimental design is as shown in Table 2. The independent variable was type of exercise (control group, yoga, and Pilates group), and the dependent variables were the participants' scores on the functional movement screen (FMS) and the individual health status survey.

\section{Measurements}

FMS scores and the short form of Rand 36-Item Health Survey (SF-36) questions were administered as a pre- and a posttest.

FMS is the standard dynamic movement and FMS covering seven movements. These seven movements are deep squat, hurdle step, inline lunge, shoulder mobility, active straight leg raise and trunk stability push up, and rotary stability. This screening aims to assess upper and lower extremity flexibility and mobility, posture control, and balance. The total score is 21 with each movement scored from zero to three. A significant risk of injury in daily life is identified by scores less than 14 (Cook et al., 2006). Cook's system is widely used by a health professional for the as-

Table 2. Experimental design

\begin{tabular}{lccc}
\hline Group & Pretest & Treatment & Posttest \\
\hline Control & $0_{1}, 0_{2}$ & - & $0_{1}, 0_{2}$ \\
Yoga & $0_{1}, 0_{2}$ & $X_{1}$ & $0_{1}, 0_{2}$ \\
Pilates & $0_{1}, 0_{2}$ & $X_{2}$ & $0_{1}, 0_{2}$ \\
\hline
\end{tabular}

$O_{1}$, functional movement screen; $O_{2}$, SF-36 test; $X_{1}$, yoga program; $X_{2}$, Pilates program; SF-36, short form of Rand 36-Item Health Survey. 
Table 3. SF-36 subelements

\begin{tabular}{lcl}
\hline Subelement & Abbreviation & \multicolumn{1}{c}{ Question number } \\
\hline $\begin{array}{l}\text { Physical functioning } \\
\text { Role limitations due to physical health }\end{array}$ & RP & $3,4,5,6,7,8,9,10,11,12$ \\
$\begin{array}{l}\text { Role limitations due to emotional } \\
\text { problems }\end{array}$ & RE & $17,18,19$ \\
Energy/fatigue & EN & $23,27,29,31$ \\
Emotional well-being & EW & $24,25,26,28,30$ \\
Social functioning & SF & 20,32 \\
Pain & PA & 21,22 \\
General health & GH & $1,33,34,35,36$ \\
Health change (not included) & HC & 2 \\
\hline
\end{tabular}

SF-36, short form of Rand 36-Item Health Survey.

sessment of sports injury with high validity and reliability.

SF-36 was used to measure individual health level and health-related quality of life (Ware and Sherbourne, 1992). SF-36 includes eight health categories as follows: (a) limitations in physical activities because of health problems; (b) limitations in social activities because of physical or emotional problems; (c) limitations in usual role activities because of physical health problems; (d) bodily pain; (e) general mental health (psychological distress and well-being); (f) limitations in usual role activities because of emotional problems; (g) vitality (energy and fatigue); and (h) general health perceptions. The composition of the survey is shown in Table 3. In this study, each item utilized the Likert scale with scores from one to six. Survey scores were summed and converted to 100 using weighted calculation as described by Ware and Sherbourne (1992). For the present research, its internal consistency estimate was 0.760 , suggesting high internal consistency.

\section{Procedure}

A total of 90 volunteer participants were recruited for this study and randomly and evenly divided into three groups: Pilates, yoga, and a control group. They did fulfill SF-36 survey and measured FMS by FMS certified instructor before the experiment. The SF-36 takes within 10-15 min and FMS was measured with 7 movements within 5 to 10 min individually. The study implemented two independent exercise programs, Pilates and yoga. The Pilates group and yoga groups worked with trained instructors, with sessions of 1-hr duration 3 times per week for eight weeks at each location. The Pilates program contained core strengthening, lumbopelvic stability and flexibility exercises. These exercises were derived from the first author who was already certified international Pilates license, Balanced Body Pilates master instructor from the United States. The yoga program consisted of stretching,
Table 4. Functional movement screen by three groups

\begin{tabular}{lcc}
\hline Group & Pre & Post \\
\hline Control & $9.63 \pm 2.19$ & $9.30 \pm 1.95$ \\
Yoga & $9.60 \pm 2.24$ & $10.63 \pm 2.13$ \\
Pilates & $10.36 \pm 2.27$ & $12.43 \pm 2.13$ \\
\hline
\end{tabular}

Values are presented as mean \pm standard deviation.

Table 5. Result of the subsequent analysis using Scheffé method

\begin{tabular}{lccc}
\hline Group & Pilates & Yoga & Control \\
\hline Pilates & - & $1.80^{* *}$ & $3.13^{* * *}$ \\
Yoga & - & - & 1.33 \\
Control & - & - & - \\
${ }^{* *} P<0.01{ }^{* * *} P<0.001$. & & &
\end{tabular}

flexibility and strengthening exercises. All yoga exercises were reviewed by a yoga instructor with over 10 years of experience. All Pilates and yoga exercises were derived from well-established programs and were suitable for beginners in the 30s-40s age group. The control group did not perform any kind of organized exercises nor receive any treatment, but took the two surveys at the same 8-week intervals as the Pilates and yoga groups. Right after applying the exercise program as above, the posttest for FMS and SF-36 was taken to all participants again individually. The methodology was the same as the pretest.

\section{Data analysis}

The collected data were analyzed using PASW Statistics ver. 18.0 (SPSS Inc., Chicago, IL, USA). Analysis of variance (ANOVA) was used with pretest score to confirm uniformity in the participants prior to the treatment, and this study analyzed the differences in posttest among the three groups using ANOVA and the Scheffé test. Plus, analysis of covariance was used when there were significant differences in the pretest score of three groups.

\section{RESULTS}

\section{Differences among the three groups on the FMS}

Table 4 shows pre- and posttest scores of the control, yoga, and Pilates groups on the FMS. While there was no significant difference among the three groups $(F[2,89]=5.63, P>0.05)$ on the pretest, there was a statistically significant difference among the three groups $(F[2,89]=15.56, P<0.0001)$. As shown in Table 5, the subsequent analysis using Scheffé method also observed statistically significant differences between the control group and Pilates group $(P<0.001)$, and also between yoga group and Pilates 
Table 6. Means and standard deviations on the SF-36 by three groups

\begin{tabular}{|c|c|c|c|c|}
\hline Variable & Group & Pre & Post & Adjusted \\
\hline \multirow[t]{3}{*}{ Physical functioning } & Control & $816.67 \pm 248.91$ & $748.33 \pm 231.27$ & $774.96 \pm 18.89$ \\
\hline & Yoga & $865.00 \pm 153.77$ & $876.67 \pm 186.96$ & $863.35 \pm 18.81$ \\
\hline & Pilates & $865.00 \pm 135.28$ & $930.00 \pm 117.88$ & $916.68 \pm 18.81$ \\
\hline \multirow[t]{3}{*}{ Role limitation due to physical health } & Control & $266.67 \pm 144.64$ & $266.67 \pm 144.64$ & $292.49 \pm 10.72$ \\
\hline & Yoga & $346.67 \pm 93.71$ & $370.00 \pm 70.22$ & $337.72 \pm 10.81$ \\
\hline & Pilates & $293.33 \pm 114.27$ & $360.00 \pm 81.37$ & $366.46 \pm 10.57$ \\
\hline \multirow[t]{3}{*}{ Role limitation due to emotional problems } & Control & $220.00 \pm 109.54$ & $216.67 \pm 108.54$ & $229.42 \pm 8.18$ \\
\hline & Yoga & $276.67 \pm 67.89$ & $280.00 \pm 61.03$ & $252.10 \pm 8.37$ \\
\hline & Pilates & $216.67 \pm 98.55$ & $276.67 \pm 62.61$ & $291.81 \pm 8.20$ \\
\hline \multirow[t]{3}{*}{ Energy } & Control & $180.00 \pm 61.25$ & $176.67 \pm 46.41$ & $188.87 \pm 6.96$ \\
\hline & Yoga & $218.00 \pm 34.18$ & $236.00 \pm 41.82$ & $227.00 \pm 6.88$ \\
\hline & Pilates & $207.33 \pm 63.35$ & $278.00 \pm 54.16$ & $274.92 \pm 6.79$ \\
\hline \multirow[t]{3}{*}{ Emotional well-being } & Control & $284.00 \pm 83.94$ & $280.00 \pm 74.28$ & $292.13 \pm 7.46$ \\
\hline & Yoga & $325.33 \pm 44.55$ & $333.33 \pm 47.08$ & $316.91 \pm 7.53$ \\
\hline & Pilates & $295.33 \pm 77.31$ & $374.00 \pm 65.42$ & $378.30 \pm 7.40$ \\
\hline \multirow[t]{3}{*}{ Social functioning } & Control & $132.50 \pm 48.76$ & $132.50 \pm 48.76$ & $129.85 \pm 3.92$ \\
\hline & Yoga & $128.33 \pm 26.04$ & $138.33 \pm 28.42$ & $138.74 \pm 3.92$ \\
\hline & Pilates & $125.83 \pm 40.73$ & $162.50 \pm 26.87$ & $164.74 \pm 3.92$ \\
\hline \multirow[t]{3}{*}{ Pain } & Control & $139.33 \pm 49.04$ & $138.67 \pm 47.67$ & $138.27 \pm 4.94$ \\
\hline & Yoga & $142.50 \pm 29.15$ & $148.33 \pm 38.02$ & $145.43 \pm 4.94$ \\
\hline & Pilates & $134.67 \pm 38.82$ & $166.67 \pm 37.77$ & $169.96 \pm 4.94$ \\
\hline \multirow[t]{3}{*}{ General health } & Control & $263.33 \pm 92.79$ & $239.17 \pm 84.00$ & $240.91 \pm 11.37$ \\
\hline & Yoga & $273.33 \pm 40.44$ & $318.33 \pm 70.38$ & $313.80 \pm 11.38$ \\
\hline & Pilates & $261.67 \pm 87.03$ & $340.83 \pm 80.54$ & $343.62 \pm 11.37$ \\
\hline \multirow[t]{3}{*}{ Health change } & Control & $40.33 \pm 15.37$ & $39.16 \pm 15.65$ & $41.04 \pm 2.85$ \\
\hline & Yoga & $50.00 \pm 6.56$ & $53.33 \pm 14.28$ & $48.43 \pm 2.93$ \\
\hline & Pilates & $39.17 \pm 20.43$ & $68.33 \pm 25.37$ & $71.40 \pm 2.87$ \\
\hline \multirow[t]{3}{*}{ Total } & Control & $2,343.34 \pm 678.68$ & $2,237.83 \pm 603.46$ & $2,232.72 \pm 45.09$ \\
\hline & Yoga & $2,625.83 \pm 296.79$ & $2,754.72 \pm 368.22$ & $2,636.57 \pm 44.67$ \\
\hline & Pilates & $2,439.00 \pm 524.88$ & $2,957.00 \pm 380.23$ & $2,979.88 \pm 44.67$ \\
\hline
\end{tabular}

SF-36, short form of Rand 36-Item Health Survey.

$\operatorname{group}(P<0.01)$.

Differences among the three groups on the individual health level (SF-36)

Table 6 shows pre- and posttest scores of the control, yoga, and Pilates groups on the SF-36. All groups except for control group increased from pre- to posttest on SF-36. However, since the pretest showed that there was significant differences between the three groups in the health condition $(F[2,89]=4.40, P<0.05)$, role limitation due to physical health $(F[2,89]=3.49, P<0.05)$, role limitation due to emotional problems $(F[2,89]=3.89, P<0.05)$, and energy variables $(F[2,89]=3.87, P<0.05)$, we conducted covariance analysis by controlling the pretest scores.

As a result of the ANOVA for the three groups after controlling the pretest by covariance, the main effect was each $F=30.69(P<$ $0.001) ; F=14.32(P<0.001) ; F=12.29(P<0.001) ; F=15.05(P<$ $0.001) ; F=21.37(P<0.001) ; F=11.29(P<0.001) ; F=36.08(P<$ $0.001) ; F=39.20(P<0.001) ; F=21.62(P<0.001)$; and $F=52.36$ $(P<0.001)$ from health change to total, indicating that there were all significant differences in subscales and total score among the three groups according to the exercise method. The results of the Scheffé posttest are shown in Table 7 to determine which exercise method difference is due to differences among groups. As a result of the covariance analysis, the results of the posttest on the predicted values of adjusted role limitation due to emotional problems, general health, and total showed a significant difference between Pilates and yoga, and Pilates and control groups. However, there was no difference between yoga and control groups. There- 
Table 7. Result of the subsequent analysis using Scheffé method

\begin{tabular}{|c|c|c|c|c|}
\hline Variable & Group & Pilates & Yoga & Control \\
\hline \multirow[t]{3}{*}{ Physical functioning } & Pilates & & 53.55 & $181.67^{* * *}$ \\
\hline & Yoga & & & $128.33^{* *}$ \\
\hline & Control & & & \\
\hline \multirow{3}{*}{$\begin{array}{l}\text { Role limitation due to } \\
\text { physical health }\end{array}$} & Pilates & & -10.00 & $93.33^{* * *}$ \\
\hline & Yoga & & & $103.33^{* * *}$ \\
\hline & Control & & & \\
\hline \multirow{3}{*}{$\begin{array}{l}\text { Role limitation due to } \\
\text { emotional problems }\end{array}$} & Pilates & & $63.33^{* *}$ & $60.00^{* * *}$ \\
\hline & Yoga & & & -3.33 \\
\hline & Control & & & \\
\hline \multirow[t]{3}{*}{ Energy } & Pilates & & $59.33^{* * *}$ & $101.33^{* * *}$ \\
\hline & Yoga & & & $42.00^{* * *}$ \\
\hline & Control & & & \\
\hline \multirow[t]{3}{*}{ Emotional well-being } & Pilates & & $53.33^{* * *}$ & $94.00^{* * *}$ \\
\hline & Yoga & & & $40.67^{* *}$ \\
\hline & Control & & & \\
\hline \multirow[t]{3}{*}{ Social functioning } & Pilates & & 5.83 & $30.00^{* *}$ \\
\hline & Yoga & & & $24.17^{* *}$ \\
\hline & Control & & & \\
\hline \multirow[t]{3}{*}{ Pain } & Pilates & & 9.67 & $29.00^{* *}$ \\
\hline & Yoga & & & 18.33 \\
\hline & Control & & & \\
\hline \multirow[t]{3}{*}{ General health } & Pilates & & $79.17^{* * *}$ & $101.67^{* * *}$ \\
\hline & Yoga & & & 22.50 \\
\hline & Control & & & \\
\hline \multirow[t]{3}{*}{ Health change } & Pilates & & $15.00^{* * *}$ & $29.17^{* * *}$ \\
\hline & Yoga & & & $14.17^{* * *}$ \\
\hline & Control & & & \\
\hline \multirow[t]{3}{*}{ Total } & Pilates & & $516.50^{* * *}$ & $719.17^{* * *}$ \\
\hline & Yoga & & & 202.67 \\
\hline & Control & & & \\
\hline
\end{tabular}

${ }^{* *} P<0.01 .{ }^{* * *} P<0.001$.

fore, it can be seen that Pilates is the most effective exercise method tested for improving role limitation due to emotional problems, general health, and total. And there was a significant difference between Pilates and yoga, Pilates and control, and yoga and control groups in energy, emotional well-being, and health condition, and there was a significant difference between Pilates and control, and yoga and control groups in physical functioning, role limitations due to physical health, and social functioning, and was a significant difference between Pilates and control groups in pain.

\section{DISCUSSION}

The purpose of this study was to examine the effects of functional movements and individual health level including physical and psychological issues for Pilates and yoga participants in their 30 s and 40 s, therefore we assessed any differences between Pilates, yoga, and control groups.

First, our result showed that the Pilates group had significantly higher improvement on FMS than either yoga and control groups. This result partially supports studies of Laws et al. (2017) and Mazloum et al. (2018). According to Laws et al. (2017), doing clinical Pilates for 6 weeks significantly improved functional movement in recreational runners. A study by Mazloum et al. (2018) showed greater improvement in the Pilates group for pain and range of motion than for extension-based motion. The FMS is in line with the study by Mazloum et al. (2018) in that it can be used to assess fundamentalw movement patterns by identifying range limitation of motion and muscle imbalance (Tomes and Lewis, 2019).

FMS can be also used to evaluate physical dysfunction and asymmetry individually. The test of principle was based on individual dynamic movement including balance, stability, and mobility. FMS can be also used to evaluate physical dysfunction and asymmetry individually. The test of principle was based on individual dynamic movement including balance, stability, and mobility. FMS revealed that improvements occur after doing Pilates exercise. This is likely due to Pilates incorporation of dynamic movements requiring balance, stability, and mobility together while yoga is more of a static exercise. Additionally, the six principles of Pilates (breathing, centering, concentration, control, precision, flow what Joseph Pilates insisted) likely contributed to the development of awareness of movement and motor sense that impact functional movements. Additional research for other age will be helpful in supporting this conclusion.

Second, the Pilates group showed significantly greater improvement on SF-36 score than either yoga or control groups. More specifically, looking at the results of the subvariables of SF-36, the Pilates group showed significantly greater improvement on SF-36 score than both yoga and control groups, or one of either group. More specifically, looking at the results of the subvariables of SF36, Pilates group showed significantly more gains than both yoga and control groups in RE (role limitations due to emotional problem), energy, emotional well-being, general health, health change, and total score.

However, the following variables such as physical functioning, $\mathrm{RP}$ (role limitations due to physical health), and social functioning showed that Pilates group was higher than the control group but not significantly different form the yoga group, and yoga group was significantly higher than control group. In the pain variable, 
only Pilates group was significantly higher than control group.

This result corresponds with the result of Küçük and Livanelioglu (2015) who found that Pilates had significant effects on changing healthy women's exercise perception and also improved psychosocial factors compare to a verbal education group and a control group. In this study, they found some improvements in the verbal education group relative to the control group but still found that there were more substantial changes in the clinical Pilates group in not only SF-36 but also other tests of psychosocial factors including Rosenberg self-esteem scale, Body Cathexis Index, Beck Depression Scale, and visual analogue scale for tiredness. Their study did not include a yoga group, highlighting the need to extend this research to different exercise methods. Also, we need to extend variables like Küçük and Livanelioglu (2015) did with psychosocial factors so as to compare Pilates and yoga.

Other studies also support the relationship we found examining quality of life using SF-36. For example, a Pilates group was shown to make greater improvement in the health-related quality of life in older people than static stretching (Campos de Oliveira et al., 2015). The study of Karaman et al. (2017) found that a Pilates-based exercise group had significant improvements in terms of physical function, physical role restriction and physical component scores compared to a standard exercise group for individuals recovering from knee arthroplasty.

In conclusion, we found through our study by examining healthy adults without any disease or any physical limitation that Pilates group showed the greatest improvements in functional movement and individual health level through SF-36 scores than yoga and control groups. However, these studies still need to have follow-up research in order to prove Pilates has a positive impact on individual health and quality of life by applying every age.

\section{CONFLICT OF INTEREST}

No potential conflict of interest relevant to this article was reported.

\section{REFERENCES}

Adams C. Physical and mental health benefits of yoga, barre, Pilates \& spinning [Internet]. RIPPED.ME; 2018 Dec [cited 2019 Apr 19]. Available from: https://ripped.me/physical-and-mental-health-benefits-ofyoga-barre-pilates-spinning/.

Campos de Oliveira L, Gonçalves de Oliveira R, Pires-Oliveira DA. Effects of Pilates on muscle strength, postural balance and quality of life of older adults: a randomized, controlled, clinical trial. J Phys Ther Sci 2015;27:871-876.

Cook G, Burton L, Hoogenboom B. Pre-participation screening: the use of fundamental movements as an assessment of function - part 1. N Am J Sports Phys Ther 2006;1:62-72.

Duggal NA, Pollock RD, Lazarus NR, Harridge S, Lord JM. Major features of immunesenescence, including reduced thymic output, are ameliorated by high levels of physical activity in adulthood. Aging Cell 2018; $17: e 12750$.

Irez GB, Ozdemir RA, Evin R, Irez SG, Korkusuz F. Integrating pilates exercise into an exercise program for $65+$ year-old women to reduce falls. J Sports Sci Med 2011;10:105-111.

Karaman A, Yuksel I, Kinikli GI, Caglar O. Do Pilates-based exercises following total knee arthroplasty improve postural control and quality of life? Physiother Theory Pract 2017;33:289-295.

KauricKlein Z. Effect of yoga on physical and psychological outcomes in patients on chronic hemodialysis. Complement Ther Clin Pract 2019; 34:41-45.

Klerman GL. Depression in the medically ill. Psychiatr Clin North Am 1981;4:301-317.

Küçük F, Livanelioglu A. Impact of the clinical Pilates exercises and verbal education on exercise beliefs and psychosocial factors in healthy women. J Phys Ther Sci 2015;27:3437-3443.

Laws A, Williams S, Wilson C. The Effect of clinical Pilates on functional movement in recreational runners. Int J Sports Med 2017;38:776-780.

Mazloum V, Sahebozamani M, Barati A, Nakhaee N, Rabiei P. The effects of selective Pilates versus extension-based exercises on rehabilitation of low back pain. J Bodyw Mov Ther 2018;22:999-1003.

Mental Healthy. Pilates, a total mind and body workout [Internet]. Mental Healthy; 2019 [cited 2019 Apr 19]. Available from: http://www.mentalhealthy.co.uk/home/about-us.

Rahimimoghadam Z, Rahemi Z, Sadat Z, Mirbagher Ajorpaz N. Pilates exercises and quality of life of patients with chronic kidney disease. Complement Ther Clin Pract 2019;34:35-40.

Siqueira Rodrigues BG, Ali Cader S, Bento Torres NV, Oliveira EM, Martin Dantas EH. Pilates method in personal autonomy, static balance and quality of life of elderly females. J Bodyw Mov Ther 2010;14:195-202.

Tomes CD, Lewis MD. Effects of personal body armor on functional movement capability. Int J Exerc Sci 2019;12:536-546.

Vancini RL, Rayes ABR, Lira CAB, Sarro KJ, Andrade MS. Pilates and aerobic training improve levels of depression, anxiety and quality of life in overweight and obese individuals. Arq Neuropsiquiatr 2017;75:850857.

Ware JE Jr, Sherbourne CD. The MOS 36-item short-form health survey (SF-36). I. Conceptual framework and item selection. Med Care 1992; 
30:473-483.

World Health Organization. Constitution of the World Health Organization - Basic Documents, Forty-fifth edition, Supplement [Internet].
Geneva (Switzerland): World Health Organization; 2006 Oct [cited 2019 Apr 19]. Available from: https://www.who.int/governance/eb/ who_constitution_en.pdf. 